\title{
Analysis of natural and man-made accidents happened in subway stations and trains: based on statistics of accident cases
}

\author{
Heng $\mathrm{Yu}^{1}{ }^{,}$, Yimin Wang ${ }^{1}$, Peiyun $\mathrm{Qiu}^{2}$, and Jiacheng Chen ${ }^{2}$ \\ ${ }^{1}$ School of Civil Engineering and Transportation, South China University of Technology, Tianhe \\ District, Guangzhou, Guangdong Province, China \\ ${ }^{2}$ Guangzhou Metro Group Co., Ltd. Wansheng Plaza, 1238 Xingang East Road, Haizhu District, \\ Guangzhou, Guangdong Province, China
}

\begin{abstract}
Sometimes subway stations and trains can be very crowded for large passenger flows. However, some stations and trains may be vulnerable when natural or man-made disasters happen, thus the safety of passengers and stuff is threatened. Therefore, it is meaningful to make a deep analysis to these disasters that may happen in subway stations and trains. By collecting cases of accidents include fire disaster, terrorist attack, flood, earthquake and stampede that happened in subway stations or on trains around the world, the causes, consequence and their own characters were analysed. Besides, some recommendations and beneficial measures aim to prevent these disasters mentioned above were also presented and discussed.
\end{abstract}

\section{Background}

In recent years, subway has become the first choice for many cities to solve traffic problems for its advantages of high efficiency, large capacity, low pollution and punctual arrivals. However, the large number of passengers make some subway stations and subway trains become "crowded places", especially in peak hours. For example, the real transportation capacity of some lines and some stations in China have exceeded the designed transportation capacity during morning and evening peak hours [1,2].

However, when emergency or disasters happen in "crowded places", the results can be serious. Most subway stations are located underground, natural disasters such as flood and earthquake may cause serious influence to them. Besides, man-made disasters such as fire, terrorism attack can also result in devastating consequence. Worse while, most subway stations are confined spaces with just a few exit channel to the outside, the distance from platforms and tunnels to safe places can be very long, the long distance may make rescue work and evacuation harder. So it's helpful to know the characteristics of each kind of disaster the subway station may face. In this paper, natural and man-made accidents cases include fire disaster, terrorist attack, flood, earthquake and stampede which happened in the

\footnotetext{
* Corresponding author: ctyuheng@mail.scut.edu.cn
} 
subway stations and trains around the world are collected. These accidents are analyzed, and some measures aim to prevent these disasters are presented and discussed.

\section{Static and analysis of subway accidents}

\subsection{Fire}

Most subway stations are relatively confined underground spaces. If fire happens in such places, the smoke caused by the burning of synthetic materials can be toxic and also make it difficult for passengers to find escape routes, thus may results in serious injury [3]. King's Cross Station fire in London happened in 1987 and Daegu Subway fire happened in 2004 both caused more than 100 deaths or injuries [4, 5]. By literature review and news gathering, 42 subway fire cases around the world are collected and listed in table $1[6,7]$.

Table 1. Subway fire disasters around the world.

\begin{tabular}{|l|l|l|c|c|}
\hline \multicolumn{1}{|c|}{ Date } & \multicolumn{1}{|c|}{ City } & & Deaths & Injuries \\
\hline 1969.11 .11 & Beijing & electric locomotive failure & 6 & 200 \\
\hline 1973.03 .27 & Paris & arson & 2 & 0 \\
\hline 1974.01 & Montréal & short circuit & 0 & 0 \\
\hline 1975.07 & Boston & lighting line failure in tunnel & 0 & 0 \\
\hline 1976.05 & Lisbon & locomotive failure & 0 & 0 \\
\hline 1976.10 & Toronto & arson & 0 & 0 \\
\hline 1978.10 & Cologne & cigarette butts & 0 & 8 \\
\hline 1979.01 & San Francisco & short circuit & 1 & 56 \\
\hline 1979.03 & Paris & short circuit of car & 0 & 26 \\
\hline 1979.09. & Philadelphia & transformer failure & 0 & 178 \\
\hline 1979.09 & New York & cigarette butts & 0 & 4 \\
\hline 1980.04 & Hamburg & seat catch fire & 0 & 4 \\
\hline 1980.06 & London & cigarette butts & 1 & 0 \\
\hline 1981.06 & Moscow & circuit failure & 7 & 0 \\
\hline 1981.09 & Bonn & staff operation mistake & 0 & 0 \\
\hline 1982.03 & New York & transmission equipment failure & 0 & 86 \\
\hline 1982.06 & New York & arson & 0 & 0 \\
\hline 1982.08 & London & short circuit & 0 & 15 \\
\hline 1983.08 & Nagoya & rectifier failure & 3 & 3 \\
\hline 1983.09 & Munich & circuit failure & 0 & 7 \\
\hline 1984.09 & Hamburg & seat catch fire & 0 & 1 \\
\hline 1984.11 & London & warehouse catch fire & 0 & 18 \\
\hline 1985.04 .12 & Paris & garbage on fire & 0 & 6 \\
\hline 1985.09 & Tokyo & locomotive bearing failure & 0 & 0 \\
\hline 1987.11 .18 & London & technical failure & 32 & over 100 \\
\hline 1991.04 .16 & Zurich & short circuit of subway locomotive & 0 & 58 \\
\hline 1991.06 & Berlin & arson & 0 & 18 \\
\hline 1994.06 & Taipei & substation catch fire & 103 & 3 \\
\hline 1995.10 .28 & Baku & caused by electrical malfunction & 289 & 270 \\
\hline 1995.04 .28 & Daegu & gas pipeline leakage & 0 & 27 \\
\hline 2001.08 .30 & Sao Paulo & unknown & 0 & 0 \\
\hline 2003.02 .18 & Daegu & arson in the subway train & & 148 \\
\hline 2003.12 .30 & Shanghai & the fire of neighboring mall & 0 \\
\hline 2004.01 .05 & Hong Kong & arson in the car & unknown & 0 \\
\hline 2005.08 .26 & Beijing & unknown & 0 \\
\hline 2006.08 .16 & New York & & 0 & 15 \\
\hline & & & 0 & 0 \\
\hline
\end{tabular}




\begin{tabular}{|l|l|l|c|c|}
\hline 2012.03 .14 & Kiev & chandelier line catch fire & 0 & 0 \\
\hline 2013.06 .05 & Moscow & short circuit & 0 & 52 \\
\hline 2014.01 .05 & Nanjing & flammable material brought by passenger & 0 & 0 \\
\hline 2015.01 .12 & Washington & unknown & 1 & 2 \\
\hline 2016.01 .22 & Shanghai & neighboring shop catch fire & 0 & 0 \\
\hline 2016.01 .26 & Tokyo & something burns at vent & 0 & 0 \\
\hline
\end{tabular}

\subsubsection{Causes of fire}

The proportion of each kind of fire causes are shown in figure 1. As shown in the figure, power line failure, mechanical equipment failure, arson are the top 3 causes of subway fire, with a proportion of $26.19 \%, 16.67 \%$ and $14.29 \%$ respectively.

Many different electrical devices and power lines are installed in the tunnel, platform, train and station hall. Short circuit, heavy load, leakage of power or equipment failure can result in fire disaster. In order to avoid these kinds of fire, regular inspection of the equipment and power lines should be carry out, and the hidden dangers should be eliminated timely. 6 subway fire were caused by arson in these cases. In some cities, there is no security check at the entrances of subway stations. Security check is an effective way to keep flammable material such as gasoline out of a subway station. So strict security check for both passengers and luggage are suggested to set up at all the entrances of a subway stations during the important days or everyday according to the safety condition of the city.
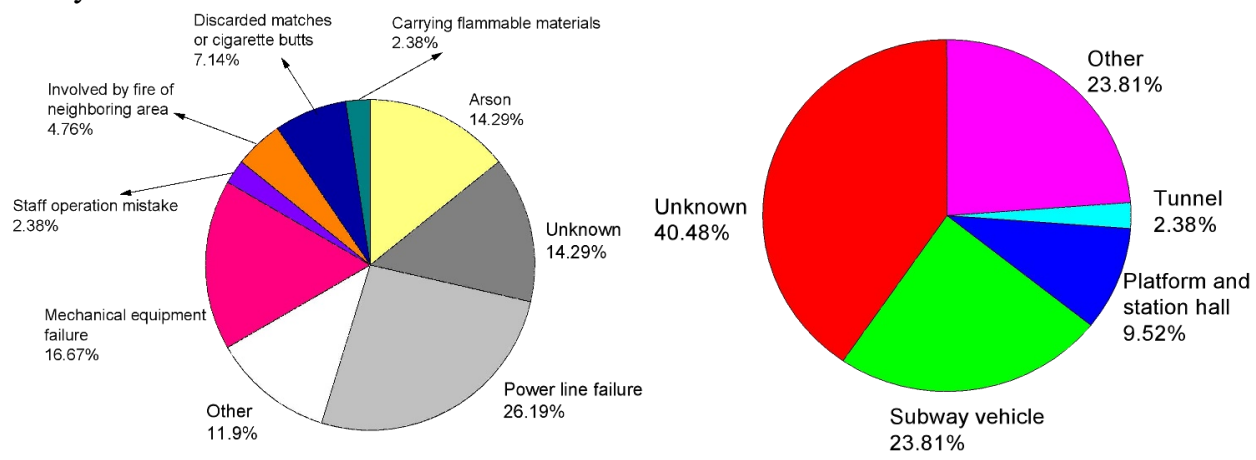

Fig. 1. Proportion of fire causes.

Fig. 2. Proportion of fire start locations.

\subsubsection{Location of fire begin}

The locations where fire first began in 17 out of 42 cases are unknown due to information shortage. The proportion of fire first began in tunnel, platform and station hall, subway train and other places such as warehouse are shown in figure 2. Fire first began on the train in 10 cases, account for $23.81 \%$ of all cases. Due to mechanical failure or electrical failure, some old subway trains may catch fire easily. Besides, the interior decoration, floor and seats of some old trains may not made of non-combustible material. Also the flammable material brought by the passengers may cause fire on the train. The proportion of fires started in tunnel, platform and station hall are $2.38 \%$ and $9.52 \%$ respectively, which are much less than fires began on the train. So subway train is suggested to be treated as a strict fireproof area with priority to station hall and platform.

\subsection{Terrorist attack}


Terrorism generally refers to the acts of violence, including bombings, assassinations, hostage-taking, aircraft hijackings or intimidation, targeting civilians and non-combatants with the aim of threatening the government and creating a climate of terror $[8,9]$. The subway station is a crowded place with just several accesses to the outside, which makes the subway station an ideal place for attacks in the eyes of terrorists. The result of terrorist attack in a closed space with large number of people can be disastrous. In order to make a clear understanding to the subway terrorist attacks, analysis based on statistic were made in this paper. Subway terrorist attack cases in cities around the world from 1976-2016 are listed in table 2, and these accidents are extracted from the Database of Worldwide Terrorism Incidents [10].

Table 2. Subway terrorism attacks around the world.

\begin{tabular}{|c|c|c|c|c|}
\hline Date & City & Tactics & Deaths & Injuries \\
\hline 1976.01 .12 & New York & explosives & 0 & 0 \\
\hline 1977.01 .08 & Moscow & explosives & 7 & 37 \\
\hline 1986.09 .04 & Paris & explosives & 0 & 0 \\
\hline 1990.07 .06 & London & explosives & 0 & 0 \\
\hline 1994.03 .19 & Baku & suicide bombings & 14 & 49 \\
\hline 1994.06 .03 & Baku & remote-detonated explosive & 13 & 42 \\
\hline 1995.03 .20 & Tokyo & deadly gas sarin & 12 & near 6000 \\
\hline 1995.07 .25 & Paris & explosives & 8 & 80 \\
\hline 1995.08 .26 & Lyon & explosives & 0 & 0 \\
\hline 1995.10 .17 & Paris & explosives & 0 & 29 \\
\hline 1998.01.01 & Moscow & remote-detonated explosive & 0 & 3 \\
\hline 1998.06.03 & Caracas & explosives & 0 & 0 \\
\hline 1998.07 .02 & Caracas & explosives & 0 & 0 \\
\hline 1999.02 .17 & Istanbul & fire or firebomb & 0 & 0 \\
\hline 1999.04 .11 & Moscow & explosives & 0 & 0 \\
\hline 2000.08 .20 & Caracas & explosives & 0 & 0 \\
\hline 2000.08 .23 & Caracas & explosives & 0 & 0 \\
\hline 2001.08 .02 & Caracas & explosives & 0 & 0 \\
\hline 2001.08 .14 & Rome & explosives & 0 & 0 \\
\hline 2001.09 .02 & Montréal & poisonous gas & 0 & over 40 \\
\hline 2002.03 .02 & Medellin & explosives & 0 & 9 \\
\hline 2002.05 .12 & Milan & Gas canister for the kitchen & 0 & 0 \\
\hline 2002.06 .02 & Lyubertsky & remote-detonated explosive & 0 & 1 \\
\hline 2002.12 .01 & Caracas & explosives & 0 & 0 \\
\hline 2003.07 .16 & Moscow & explosives & 0 & 0 \\
\hline 2004.02 .06 & Moscow & suicide bombings & 40 & 120 \\
\hline 2004.03 .11 & Madrid & explosives & 192 & 2050 \\
\hline 2004.08 .31 & Moscow & explosives & 10 & 50 \\
\hline 2005.07 .07 & London & suicide bombings & 56 & 784 \\
\hline 2006.07 .11 & Bombay & explosives & 209 & over 700 \\
\hline 2008.11 .25 & St. Petersburg & explosives & 3 & 2 \\
\hline 2010.03 .29 & Moscow & suicide bombings & 40 & 102 \\
\hline 2011.04 .11 & Minsk & explosives & 15 & 204 \\
\hline 2014.06 .25 & Cairo & explosives & 7 & over 100 \\
\hline 2014.09 .08 & Santiago & explosives & 0 & 14 \\
\hline 2015.12 .01 & Istanbul & explosives & 2 & 1 \\
\hline 2016.03 .22 & Brussels & suicide bombings & 35 & 340 \\
\hline 2016.09 .28 & Tokyo & unknown gas & 0 & 9 \\
\hline
\end{tabular}




\subsubsection{Geographical distribution}

Figure 3 shows the geographical distribution of subway terrorist attack cases. Europe include Russia is the area with the largest number of subway terrorist attacks. The frequent happening of terrorist attacks in this area has a relationship with the non-strict arms control policy, refugees' issues and illegal immigration. Few subway attacks were reported in cities of East Asia currently. However, the subway in Tokyo, Seoul, Shanghai, Beijing and Guangzhou are all very busy and crowded subway systems, and some separatist forces, cult organization and terrorist organizations are in active at present, so attentions should also be paid to prevent subway terrorist attacks in these cities.

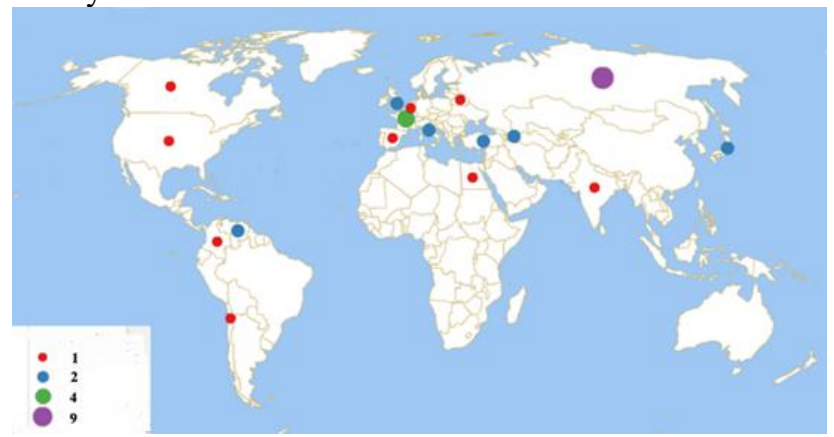

Fig. 3. Times of subway terrorist attack around the world (By country, 1976-2016).

\subsubsection{Time distribution}

Time distribution of the 38 subway terrorist attack cases is shown in figure 4 . As can be seen from the graph, none subway terrorist attacks happened except two before the year of 1986. However, after 1986, the subway terrorist attacks gradually increased. In the 5 years during 2001 to 2005, 12 subway terrorist attacks were recorded. Subway terrorist attacks become less after the year of 2005 . However, the number of subway terrorist attacks began to rise again from 2011.Terrorist attacks usually result in serious damage, so the subway station managers should be always on alert.

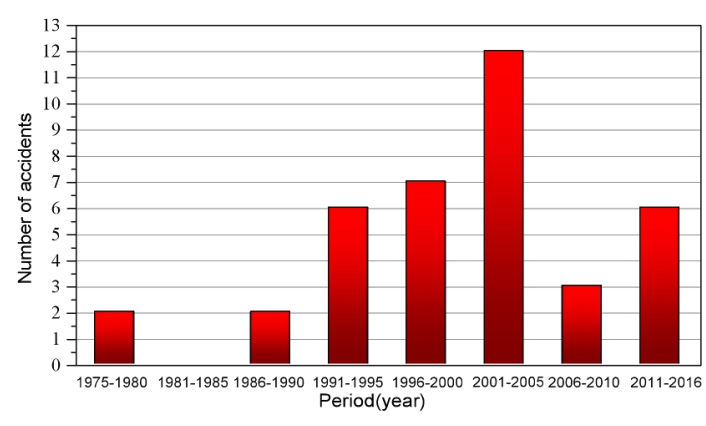

Fig. 4. Subway attacks in different time periods

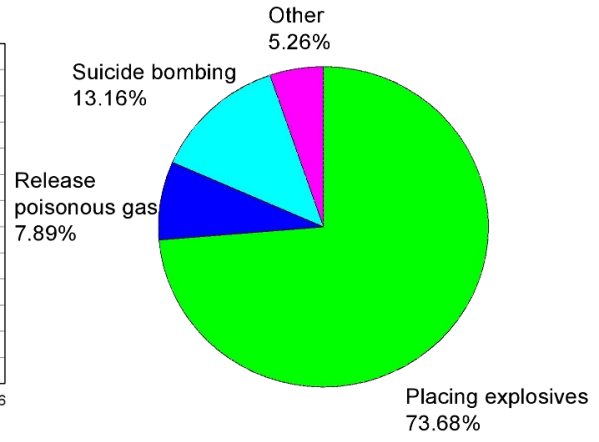

Fig. 5. Proportion of attack tactics.

\subsubsection{Attack tactics}

The common tactics used by terrorist include bombing, sabotage, armed attacks, arson, landmine and threat [11]. However, according to the statistics of the attack cases, placing explosives, suicide bombings and release poisonous gases are the three main types of 
subway attack tactics adopted by terrorist. The proportion of each kind of attack tactics are shown in figure 5.

As described in the preceding paragraph, placing explosives is the main method of subway attack adopted by terrorists, which accounts for $73.68 \%$ of all gathered cases. Usually, explosive can cause large number of casualties and deaths in a short time, and also can make passengers fall into panic easily. Terrorist attack such as London Underground bombings in 2005 and Moscow Metro bombings in 2010 both caused dozens of death and hundreds of injuries. After the poisonous gas attack in 1995 in Tokyo metro system, some measures are taken by Tokyo metro, and after that few accidents were reported to happen in the Tokyo metro system. The measures are listed below [12]:

- Security cameras with full coverage are required to be installed in all subway stations.

- Trash cans in the subway stations should be transparent, so the contents are visible.

- The posters and broadcast are used in the subway station and train to inform passengers to ask for cooperation when suspicious objects are found.

- Security patrols are carried out by the station attendants and security guards.

\subsection{Flood}

In some developing countries, urban environments can be vulnerable to flood due to extreme climate and rapid urbanization [13]. Rainstorm in summer will cause flood in cities when the drainage system overloaded. Most subway stations and rails are located underground, the water can flow into the stations and tunnels through the station accesses and tunnel exits in the condition the waterproof facilities are not working well. Too much water in the station and tunnel will lead to the close of a station or even the entire subway line out of service. In early years, less attention was paid to the possibility of being flooded for subway systems, which makes some subway stations vulnerable during rainstorm [14, 15]. In order to know better about the subway flood, 13 flood accidents of subway station in different cities are collected in this paper. The time, location, causes and consequences of these accidents are listed in table 3.

Table 3. Flood accidents of subway stations around the world.

\begin{tabular}{|l|l|l|l|}
\hline \multicolumn{1}{|c|}{ Date } & \multicolumn{1}{|c|}{ City } & \multicolumn{1}{c|}{ Cause } & \multicolumn{1}{c|}{ Consequence } \\
\hline 2001.09 .17 & Taipei & Typhoon & Water flew into stations and shopping area via tunnel. \\
\hline 2002.08 & Prague & Rainfall & About 20 km of lines and 19 stations were soaked. \\
\hline 2004.09 .09 & New York & Hurricane & Water in stations, several subway lines were closed. \\
\hline 2007.08 .08 & New York & Rainstorm & The subway system heavily flooded. \\
\hline 2008.07 .06 & Beijing & Rainstorm & Line 2 out of service. \\
\hline 2011.06 .23 & Beijing & Rainstorm & Cable was soaked in rain water, causing a short circuit. \\
\hline 2011.08 .23 & Nanjing & Rainstorm & Water flew into the tunnel. \\
\hline 2012.07 .21 & Beijing & Rainstorm & Water caused the induction board work improperly. \\
\hline 2012.10 .30 & New York & Hurricane & Many subway tunnels were inundated with floodwater. \\
\hline 2014.08 .25 & Busan & Rainstorm & Some sections of line1, line2 and Line4 were flooded. \\
\hline 2014.08 .31 & New York & Rainstorm & Some subway stations flooded. \\
\hline 2016.05 .10 & Guangzhou & Rainstorm & Water flow into Changban station through entrance. \\
\hline 2016.07 .06 & Wuhan & Rainstorm & Several stations of Line 4 were flooded. \\
\hline
\end{tabular}


No one died or got injured in these 13 accidents. However, the operation of subway systems were affected by varying degrees in all these cases. Subway is an important transportation tool in cities, a large number of passengers travel by subway every day, so passengers' travel plan will be affected if the subway out of service due to flood. Besides, these 13 flood accidents of subway station are mainly caused by typhoon or rainstorm, so waterproof measures should be take into consideration in the design and maintenance of subway stations in cities with frequent typhoons or rainstorms. Entrances of some subway stations have the same height with the ground and no canopies were installed, during rainstorm seasons, rain and water can flow into the stations easily. In order to prevent water from entering, steps and canopies should be added at the entrances of stations built earlier.

\subsection{Earthquake}

Engineers generally hold the idea the earthquake has limited impact on the structures lies underground. However, during Kobe Earthquake in Japan in 1995, Daikai subway station, an underground station was almost destroyed [16]. Then researches focus on the impact of earthquake to subway station were carried out by some scholars [17-19]. According to their findings, the underground structures of subway station can be influenced by the earthquake. In other words, earthquakes can threat both the safety of underground stations, tunnels of subway system, thus the safety of passengers in the subway system is threatened. 6 cases of subway affected by earthquakes are collected and listed in table 4 .

As shown in table 4, earthquake with different magnitude influence the subway systems in different ways. Usually a smaller earthquakes may only force the subway train slow down or stop. But a larger earthquake can cause the overturn of the station column, even the collapse of the whole station. Meanwhile, there are no obvious indications before an earthquake. It is often too late to get prepared when earthquake suddenly occur, thus resulting in more casualties. Subway stations usually located underground, when structures destroyed or collapsed in an earthquake, both rescue or escape are not easy. So it is necessary to get prepared before an earthquake. For example, detailed emergency plans for earthquake with different magnitude is needed, so people can get well prepared more quickly when earthquake occurs. Also, knowledge about escape in an earthquake should be popularized to the public via the poster, short video, and broadcast or other ways, so when an earthquake happens, people can make a way to escape instead of falling into panic.

Table 4. Cases of subways affected by earthquake.

\begin{tabular}{|c|l|c|l|}
\hline Date & \multicolumn{1}{|c|}{ Location } & Magnitude & \multicolumn{1}{c|}{ Consequence } \\
\hline 1985.09.19 & Mexico city & 8.1 & All lines of metro were out of service. \\
\hline 1995.01.17 & Kobe, Japan & 7.3 & 5 stations damaged, about 3km tunnel collapsed. \\
\hline 2003.05 .26 & Sendai, Japan & 7 & Sendai Subway were out of service. \\
\hline 2014.05 .11 & Hualien, Taiwan & 5.9 & Taipei MRT were out of service. \\
\hline 2015.05 .25 & Kanto, Japan & 5.6 & Tokyo subway were out of service. \\
\hline 2015.10 .26 & Afghanistan & 7.8 & Delhi subway out of service, some people trapped. \\
\hline
\end{tabular}

\subsection{Stampede}

When something unusual happen in a subway station, such as earthquake or violent incidents, passengers may fall into panic and then try to escape. If there are too many people in a station, a stampede accident happens easily, and the control of the flow of crowd is difficult. Usually, the consequence of a stampede accident in a subway station is serious for the space is small, and economic loss and casualties can also be resulted. 15 
cases of stampede accidents in subway station or on train are collected and listed in table 5 . All these collected accidents happened in the mainland of China.

Table 5. Stampede in subway stations in China mainland.

\begin{tabular}{|c|l|l|}
\hline Date & \multicolumn{1}{|c|}{ Stations } & \multicolumn{1}{c|}{ Events } \\
\hline 2001.12 .04 & People's square, Shanghai & Too crowded, a woman fell down to the track \\
\hline 2007.12 .21 & Century Avenue, Shanghai & Too crowded, 5 people fell down on the escalator. \\
\hline 2009.12 .21 & Jiangsu Road, Shanghai & Escalator suddenly stopped and 7 people injured. \\
\hline 2010.08 .10 & Zhichunlu, Beijing & Too crowded in transfer channel, 1 person got hurt. \\
\hline 2010.05 .26 & Huaqianglu, Shenzhen & Goods fell down on the escalator. \\
\hline 2012.4 .26 & Olympic Green, Beijing & A man fell down on the escalator. \\
\hline 2014.03 .04 & Xicun, Guangzhou & Two young man play pepper spray on the train. \\
\hline 2014.05 .09 & Tiyu Xilu, Guangzhou & A fight in entrance channel \\
\hline 2014.06 .07 & $\begin{array}{l}\text { Shenzhen, North railway } \\
\text { station }\end{array}$ & A fight on the train, other people tried to escape. \\
\hline 2014.06 .05 & Guomao, Beijing & Some people quarrel in the transfer channel. \\
\hline 2014.06 .16 & Jiedaokou, Wuhan & A fight on the train and passengers tried to sheer. \\
\hline 2014.09 .18 & Line 4, Beijing & A riot was caused by quarrel on the train. \\
\hline 2015.04 .20 & Huangbeiling, Shenzhen & A woman fell down, passengers fell into panic. \\
\hline 2015.09 .22 & Zhuzilin, Shenzhen & A boy ran on the platform. \\
\hline 2016.05 .05 & Century Avenue, Shanghai & Dumbbells blocked the exit of escalator. \\
\hline
\end{tabular}

\subsubsection{Location of stampede}

Figure 6 shows the proportion of location where these stampede accidents happened. The proportion of stampede happened on the escalator is $33.33 \%$. People are more likely to get hurt in an elevator when it in moving. 4 accidents happened on the train, accounting for $26.67 \%$ of all cases. The space on the train is smaller and the train is completely closed, so the stampede on the train also can be very dangerous. Among these accidents, two cases should be special noticed. The first one happened in Huaqianglu station, Shenzhen on May 26, 2010. In this accident, escalator was used to carry goods with large size, and the goods fell down. Another one happened in Century Avenue Station in Shanghai on May 05, 2016. A woman put dumbbells on the escalator and she try to pick it until the escalator reach the top, then the following passengers got blocked. From these two accidents, it can be seen that it is dangerous to carrying over-sized or heavy goods by escalator and such behaviors should be prohibited.
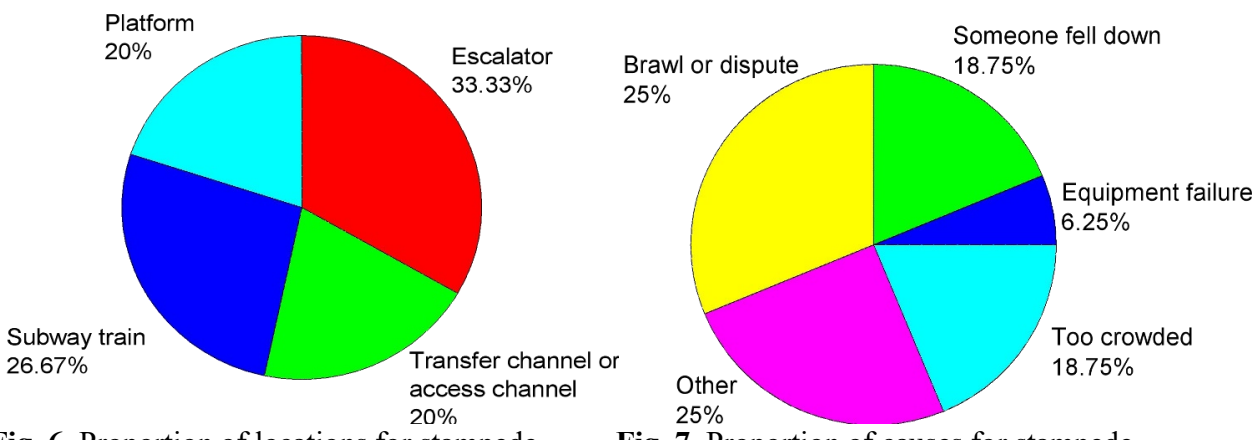

Fig. 6. Proportion of locations for stampede.

Fig. 7. Proportion of causes for stampede.

\subsubsection{Causes of stampede}

The proportion of stampede causes are shown in figure 7. The top three causes for subway stampede are brawl or dispute, too crowed and someone fell down. In order to avoid 
stampede accidents, the following improvement are suggested to be made in public safety education and station management.

- The number of passengers in a station should be controlled, if there are too many passengers in the station, then passengers out of the station should wait to get in.

- By poster, TV or broadcast, passengers should be informed to stay calm when something happens, also the right way to escape should be informed.

- When something happens, working staff in the station should get to the scene as soon as possible and try to help solve the problem.

- Carrying oversized goods or heavy goods by the escalator should be forbidden.

- The controlling centre should monitor the whole station by CCTV, if something happens, effective measures should be taken as soon as possible.

\section{Summary and recommendation}

Case statistics and analysis of different kinds of natural and man-made disasters that happened in the subway stations and on the trains were presented in this paper. According to the analysis, the following conclusions can be obtained:

1. The top three causes of fire in subway stations are power line failure, mechanical equipment failure and arson. So regular inspection and maintenance work for electrical equipment should be carried out, and strict security check for both passengers and luggage are suggested to be set at the entrances of a subway station. Most fire started on the train, the train should be treat as a key fire-preventing area.

2. Terrorist attack in subway stations are frequent in recent years, and the most common tactics adopted by terrorist are placing explosives or suicide bombings. Security check, security patrol and CCTV system are useful methods or tools to prevent terrorist attack in subway stations.

3. Some old subway stations may be flooded due to the design defects, in order to avoid flooding of subway stations, canopies and steps should be installed or added at the entrances, and flood gates should be installed at the exits of tunnels.

4. Earthquake with large may destroy the station or tunnel in varying degrees. While earthquake with smaller magnitude usually make the subway station or train out of service. So different emergency plans are suggested to be formulated in order to cope with earthquakes with different magnitudes.

5. Stampede in the subway station can be a serious disaster for some subway stations are crowded. According to the case statistics, escalator is the place where most stampede accidents happened. In order to avoid stampede, safety education and propaganda to the passengers should be carried out, also the utilization of escalator should be well managed.

\section{Acknowledgement}

The authors would like to thank the Ministry of Science and Technology (P. R. China) for its fund and support (National Key R\&D Program of China. No. 2016YFC0802500).

\section{References}

1. Shi Congling, Zhong Maohua, Nong Xingzhong, Shi Jiehong, Feng Guoguan. Modeling and safety strategy of passenger evacuation in a metro station in China. Safety Science. 50(2012)1319-1332. 
2. He, Lin, Q. Liang, S. Fang. Challenges and innovative solutions in urban rail transit network operations and management: China's Guangzhou Metro experience. Urban Rail Transit 2.1(2016):33-45.

3. Fridolf, Karl, D. Nilsson, and H. Frantzich. Evacuation of a metro train in an underground rail transportation system: flow rate capacity of train exits, tunnel walking speeds and exit choice. Fire Technology 52.5(2016):1481-1518.

4. K. Moodie. The King's Cross fire: damage assessment and overview of the technical investigation. Fire Safety Journal. 18(1992) 13-33.

5. Manabu Tsukahara, Yusuke Koshiba, Hideo Ohtani. Effectiveness of downward evacuation in a large-scale subway fire using Fire Dynamics Simulator. Tunnelling and Underground Space Technology. 26(2011) 573-581.

6. Du Bao-ling. Statistical analysis of the foreign underground fire cases. Fire Science and Technology. 26(2007)214-217(In Chinese)

7. Zarboutis, Nikos, and N. Marmaras. Searching efficient plans for emergency rescue through simulation: the case of a metro fire. Cognition, Technology \& Work 6.2(2004):117-126.

8. Schmid, Alex P, A. Jongman, and E. Price. The Routledge Handbook of Terrorism Research. Routledge Handbook of Terrorism Research. Taylor \& Francis Ltd. 2011:261-262.

9. Kaye, Dalia Dassa, et al. More Freedom, Less Terror? Liberalization and Political Violence in the Arab World. RAND Corporation, 2008.

10. Database of Worldwide Terrorism Incidents, Retrieved 10 November 2016, available from: http://www.rand.org/nsrd/projects/terrorism-incidents/about/.

11. Jean-Luc Bruyelle, et al. Improving the resilience of metro vehicle and passengers for an effective emergency response to terrorist attacks. Safety Science 62(2014)37-45.

12. Measures against railroad terrorism, Retrieved 10 November 2016, available from: http://www.tokyometro.jp/safety/prevention/terror/index.html.

13. Yin, Jie, et al. A review of advances in urban flood risk analysis over China. Stochastic Environmental Research and Risk Assessment 29.3(2015):1063-1070.

14. Suarez P, Anderson W, Mahal V, Lakshmanan T R, Impacts of flooding and climate change on urban transportation: a systemwide performance assessment of the Boston Metro area, Transportation Research Part D: Transportation and Environment. 10.3(2005)231-244.

15. Gonzva, Michaël, et al. Modeling disruptions causing domino effects in urban guided transport systems faced by flood hazards. Natural Hazards. 86.1(2017):183-201.

16. Iida, Hiroomi, et al. Damage to Daikai subway station. Soils \& Foundations Jan (2012):283-300

17. Iwatate T, Kobayashi Y, Kusu H et al (2000). Investigation and shaking table tests of subway structures of the Hyogoken-Nanbu earthquake. In: The 14th world conference on earthquake engineering, Beijing,China, Paper No.1043

18. Hashash, Youssef M. A., et al. Seismic design and analysis of underground structures. Tunnelling \& Underground Space Technology 16.4(2001):247-293

19. Haiyang Zhuang, et al. Seismic responses of a large underground structure in liquefied soils by FEM numerical modelling. Bulletin of Earthquake Engineering .13(2015) 3645-3668. 